\section{On Mathematical Towers of Babel and "Translation" as an Epistemic Category}

\section{Michael Friedman}

Years Ago features essays by historians and mathematicians that take us back in time. Whether addressing special topics or general trends, individual mathematicians or "schools" (as in schools of fish), the idea is always the same: to shed new light on the mathematics of the past. Submissions are welcome.

\footnotetext{
$>$ Submissions should be uploaded to http://tmin.edmgr.com or sent directly to Jemma Lorenat, e-mail: jlorenat@pitzer.edu.
}

n his manuscript "The Origin of Geometry," written in 1936 but published posthumously in 1939, Edmund Husserl notes the following:

The Pythagorean theorem, [indeed] all of geometry, exists only once, no matter how often or even in what language it may be expressed. It is identically the same in the "original language" of Euclid and in all "translations"; and within each language it is again the same, no matter how many times it has been sensibly uttered, from the original expression and writing down to the innumerable oral utterances or written and other documentations" (Husserl 1970, 357). ${ }^{1}$

Husserl, the founder of the school of phenomenology, was no stranger to mathematics. He obtained his $\mathrm{PhD}$ in mathematics in 1883 with a thesis "Contributions to the Calculus of Variations" [Beiträge zur Theorie der Variationsrechnung]. Hence, assuming that Husserl encountered (at least) two different proofs of the Pythagorean theorem in his mathematical studies, one has to wonder, when looking at this theorem, whether the "original" proof of Euclid and its "translations" are indeed the same. It is clear that Husserl here conflates not only the numerous proofs of the Pythagorean theorem that were already known back then, but also the dependence of those proofs on the cultural milieu, where and how those proofs were discovered and developed: taking into account the class of "all scientific constructions and the sciences themselves," he notes that "[w]orks of this class do not, like tools ... or like architectural and other such products, have a repeatability in many like exemplars" - since they exist only once (ibid., 356-357); that is, these works have what Husserl calls an "ideal' objectivity", (ibid., 356).

Although I will not discuss in this paper Husserl's philosophy of geometry, one must note that from today's perspective of the philosophy (and the history) of mathematics, and especially of the philosophy of mathematical practices, not only the use of the term "translation," but also the activity itself of translating, into, for example, a (more) formal language, is considered anachronistic, not to say misleading and distorting. As I will survey briefly at the end of this article, Thomas S. Kuhn and Peter Galison, to give two examples, criticize translation from the

\footnotetext{
1، 'Der Pythagoräische Satz, die ganze Geometrie existiert nur einmal, wie oft sie und sogar in welcher Sprache immer sie ausgedrückt sein mögen. Sie ist identisch dieselbe in der 'originalen Sprache' Euklids und in allen 'Übersetzungen'; in jeder Sprache abermals dieselbe, wie oft sie sinnlich geäußert worden ist, von der originalen Aussprache und Niederschrift an in den zahllosen mündlichen Äußerungen oder schriftlichen und sonstigen Dokumentierungen."

${ }^{2} \mathrm{~A}$ similar claim is expressed by Husserl toward the end of his article: "It is a general conviction that geometry, with all its truths, is valid with unconditioned generality for all men, all times, all peoples, and not merely for all historically actual ones but for all conceivable ones." [“Es ist eine allgemeine Überzeugung, daß die Geometrie mit allen ihren Wahrheiten in unbedingter Allgemeinheit gültig ist für alle Menschen, alle Zeiten, alle Völker, für alle nicht bloß historisch faktischen sondern überhaupt erdenklichen"'] (Husserl 1970, 377).
} 
perspective of the philosophy of science, though their solutions were different. To focus on the philosophy of mathematics, Brendan Larvor indicates that

in examining the logic of a proof, we should look at the proof in the form and the idiom in which it is used, rather than first translating it into some other idiom. It may be that the proof employs inferential moves that are possible only using precisely that kind of representation, governed by precisely those rules (Larvor 2019, 2723).

Moreover, there is sometimes, according to Larvor, a "non-universality of [the inferential] moves available in some notational or diagrammatic practice," which resists "translation into formal logic" (ibid., 2725).

Nevertheless, the question that arises is whether and how the term "translation" was actually used by mathematicians during the nineteenth and twentieth centuries. Does Husserl's view, however misleading it may be regarding how mathematics is practiced in "real life," reflect in any way the opinions of other mathematicians? Did other mathematicians employ the term "translation" as an actor's term, thus understanding it as an epistemic category to describe relationships between mathematical idioms or domains, and if so, what did they mean by it? To answer the last question, I will present three case studies from the nineteenth and twentieth centuries of mathematicians (or communities of them) who used the term "translation." The examples are taken mostly from the history of geometry and its interaction with algebra, where the term "geometry" is taken in its broader meaning, including, for example, algebraic geometry. This, let me emphasize, does not mean that there do not exist other mathematicians who used this term with respect to other areas of mathematics. The goal of this article, as will be shown in the second part, will be to explicate what was meant by the mathematicians who were using this term: were they following Husserl's view, or did they have a more restricted and local notion of translation, in the meaning of Galison's "trading zones," as I will argue at the end of this paper?

\section{“Translation" as an Actor's Term: Three Case Studies}

I will begin by considering three case studies in which the term "translation" was indeed used by mathematicians: the first from the beginning of the nineteenth century, concentrating on the rise of descriptive geometry in France; the second, which deals with how hyperbolic geometry was treated at the end of the nineteenth century; and the third, how the metaphor of the "Tower of Babel" was employed in considering twentieth-century mathematics in general and formalism in particular. I chose these case studies because they all show communities of mathematicians who were using the term in a similar fashion. ${ }^{3}$

\section{Case Study I: Descriptive Geometry: Monge, Laplace, Lacroix, and Biot}

Our first example deals with the relationships between algebra and geometry at the beginning of the nineteenth century, when the methods of algebra and analysis slowly were able to prove new results that were not predicated by geometry. The rise of descriptive geometry and the extensive use of analytic geometry signify one of these new developments. What prompted these new developments was the founding of two novel institutes in Paris: the Ecole Polytechnique, providing training for civil and military engineers, and the Ecole normale de l'an III, which was devoted to advancing teacher education. The country's best mathematicians, for example Monge, Laplace, and Lagrange, taught in both schools. The lessons given as well as the new results that were proved were often accompanied by reflections on the nature of the mathematical language.

I would like to begin with Monge, and especially how he defined the objects of descriptive geometry. ${ }^{4}$ In his teaching at the beginning of 1795, Monge emphasized in his lesson program at the École normale de l'an III the geometric visualization of mathematical and physical problems and defined the aim and objectives thus:

The first [objective] is to accurately represent, with drawings that have only two dimensions, objects that have three and are amenable to rigorous definition. From this point of view, it [descriptive geometry] is a necessary language for the man of genius who designs a project, for those who must direct its execution, and finally for the artists who must themselves execute its various parts.

The second objective of descriptive geometry is to deduce from the exact description of the [geometric] bodies everything that necessarily follows from their respective shapes and positions. In this sense, it is a way of seeking the truth (Dhombres 1992, 305-306). ${ }^{5}$

Taking this statement into consideration, and especially the "necessary [geometric] language" for the introduction of new, possibly abstract, concepts, Monge described either the concrete situations or the possible applications in which a concept appears (Sakarovitch 1998, 214). This was done through drawing and modeling. Indeed, Monge was one of the first mathematicians at the Ecole polytechnique to build

\footnotetext{
${ }^{3}$ This is also not to imply that other groups of mathematicians who used this term did not exist; as we will see at the end of the paper, the mathematician Emil Artin also used this term.

${ }^{4}$ For a recent survey of Monge's conception of descriptive geometry and how descriptive geometry spread in France, see Barbin (2019a), Barbin (2019b). Both papers contain numerous references concerning Monge and the beginning of descriptive geometry.

5'“Le premier est de représenter avec exactitude, sur des dessins qui n'ont que deux dimensions, les objets qui en ont trois, et qui sont susceptibles de définition rigoureuse. Sous ce point de vue, c'est une langue nécessaire à l'homme de génie qui conçoit un projet, à ceux qui doivent en diriger l'exécution, et enfin aux artistes qui doivent eux-mêmes en exécuter les différentes parties. Le second objet de la géométrie descriptive est de déduire de la description exacte des corps tout ce qui suit nécessairement de leurs formes et de leurs positions respectives. Dans ce sens, c'est un moyen de rechercher la vérité."
} 
three-dimensional models of mathematical surfaces, a tradition that was further developed by his student Théodore Olivier. ${ }^{6}$ Moreover, Monge emphasized the connections to practical concerns (such as the needs of the army) as well as the methods of stone carvers. He also stressed the importance of the relationships between analysis, analytic geometry, and descriptive geometry in his book Géométrie descriptive at the end of the eighteenth century:

It is not without an object that we make a comparison here between descriptive geometry and algebra .... There is no construction in descriptive geometry that cannot be translated into analysis; and if the problems have no more than three unknowns, then every analytic operation can be regarded as the script for a spectacle in geometry (Monge 1799, 16). ${ }^{7}$

It is clear that Monge thought about geometry and algebra as languages. This way of presenting the relationships between algebra and geometry, as a "translation" between languages, is also to be seen in the writings of other French mathematicians, such as Biot and Lacroix. Biot noted in 1802 that

to show how one can write down in analysis the questions of geometry, and conversely, how one can translate into geometry the results of analysis: this is the goal of the application of algebra to geometry (Biot 1802, 1). ${ }^{8}$

Three years earlier, Lacroix called for a much stronger separation between the two languages, writing:

but I would not wish to mix ... geometric considerations with algebraic calculations; it would be better ... that the results of each illuminate the other, corresponding to each other, so to speak, as the text of a book and its translation (Lacroix 1797, xxvi).?

Indeed, while Lacroix attempted to point out an equivalence between the two languages as separate but functioning as equivalent "books" that illuminate each other, ${ }^{10}$ Monge noted that this image of "translation" does not imply that it is a perfect translation, that is, the translation employed does not necessarily point toward a full equivalence between the languages: in order to translate into the geometric language, thus Monge, one must have "no more than three unknowns."11

This image of "translation" as either what may constitute a partial equivalence or as what points toward a hierarchy of languages in the sense of a hierarchy of generality is to be seen also with other teachers at the Ecole normale de l'an III, namely Lagrange and Laplace. On the one hand, Lagrange claims "without metaphor" [sans métaphore] that arithmetic and geometry are the "foundation and essence of all the sciences that treat magnitudes"12 and that one must "translate" arithmetic results into geometric ones or conversely to see how these languages complete each other (in Dhombres 1992, 211).

One may assume that by the expression "without metaphor" Lagrange means that this "translation" between the two foundations is what should be done in practice. But nevertheless, it is an equivalence that is restricted to the sciences "that treat magnitudes." On the other hand, for Laplace, "translation" occurs only into the "algebraic language"-and both expressions, "translation" and "algebraic language," are used often side by side (see, for example, Dhombres 1992, 46, $60,61,67,103)$. However, the expression "geometric language" does not appear at all in his lecture notes, hence implicitly underlining a hierarchy between the languageswhich one is more general-or even an implicit understanding of what may even be considered a language.

\section{Case Study II: Poincaré and the "Dictionary" Between Languages}

As we saw with the first example, at the beginning of the nineteenth century, several mathematicians-Lacroix, Laplace, Monge, and Biot-considered the relationship between presenting the same problem or the same theorem in both geometric and algebraic language as one of translation, though some of them noted that one language may be more powerful than the other, or that such translation can be only partial (obviously, this discussion did not end at the beginning of the nineteenth century, but seems rather to persist through descriptions of analytic geometry). That is, these mathematicians did not look at different objects and translate between them; rather, it is the same object that is considered, presented in different languages.

A similar situation occurred at the end of the nineteenth century with the rise of different "interpretations" of nonEuclidean geometries. To recall, during the first decades of the nineteenth century, the mathematicians János Bolyai and Nikolai Ivanovich Lobachevsky developed non-Euclidean geometries, in particular hyperbolic geometry. They did so by developing a geometry in which a revised parallel postulate was introduced, according to which more

\footnotetext{
${ }^{6}$ For example, Felix Klein (1926a, 78) described Olivier's models as the origin of the mathematical models of the nineteenth century.

7،'Ce n'est pas sans objet que nous comparons ici la géométrie descriptive à l'algèbre ... . II n'y a aucune construction de géométrie descriptive qui ne puisse être traduite en analyse; et lorsque les questions ne comportent pas plus de trois inconnues, chaque opération analytique peut être regardée comme l'écriture d'un spectacle en géométrie." The same phrase appears in one of Monge's lessons in 1795 at the École normale de l'an III (Dhombres 1992, 317).

s"'Montrer comment on peut écrire en analyse les questions de géométrie, et réciproquement, comment on peut traduire en géométrie les résultats de l'analyse: tel est le but de l'application de l'algèbre à la géométrie."

9،"mais je ne voudrois pas qu'on mêlât ... les considérations géométriques avec les calculs algébriques; il seroit mieux ... que les résultats de l'un et de l'autre s'éclairassent mutuellement, en se correspondant, pour ainsi dire, comme le texte d'un livre et sa traduction."

${ }^{10}$ What comes into play here is the metaphor of truth as light (cf. Blumenberg 1957), which is rather different from what the term "translation" suggests, since it does not presuppose any truth value.

${ }^{11}$ Moreover, as Sakarovitch points out $(1998,215)$, this image of the relationships between algebra as symbolic and descriptive geometry as visual disappears within the writings of descriptive geometry by the middle of the nineteenth century.

12 "le fondement et l'essence de toutes les sciences qui traitent des grandeurs...."
} 
than one line can be drawn through a given point parallel to a given line. Though neither of them proved that this new geometry is consistent, the novelty from their side (and also from Gauss, who did not publish his results) was a strong belief that other geometries were possible in addition to the Euclidean one. To make this belief concrete and more intuitive, the question was whether one could find a surface on which those geometries could be illustrated. ${ }^{13}$

In 1868 and 1869, Eugenio Beltrami published his two seminal papers "Essay on the Interpretation of Non-Euclidean Geometry" and "Fundamental Theory of Spaces with Constant Curvature." Beltrami asked whether there are two-dimensional surfaces, embedded in Euclidean space (and having another metric), that satisfy the revised parallel postulate. To answer the question in the affirmative, he constructed several surfaces of revolution (or partial such surfaces) embedded in three-dimensional Euclidean space on which the geometric theorems of the Bolyai-Lobachevsky hyperbolic plane could be easily interpreted and verified. As a result of the construction, these were surfaces of constant curvature, which Beltrami called pseudospherical. Moreover, at the beginning of the "Essay," Beltrami noted that his goal was to find a "concrete interpretation" (Beltrami, 1868, 381), that is, "to find a real substrate for this theory [of the hyperbolic plane] before admitting the need for a new order of entities and concepts to support it" (ibid., 375).

The "real substrate" is, for example, an infinite surface of revolution embedded in a three-dimensional space, but it was considered-as Moritz Epple showed-a product of "concrete" imagination, one that went beyond the traditional world of geometric illustration and visualization (Epple 2016, 23). This concretization was also materialized in the form of a physical material model, constructed out of paper (see Figure 1 and also Friedman 2018, 142-150). The material model, being an object in the physical world and hence a "concrete" object, is also what can (and should) be imagined-exactly since what is modeled is only a part of the entire surface.

For Beltrami, the use of the term "interpretation" was still rooted in the tradition of Anschaulichkeit, to be seen either in his "concrete imagination" or in his construction of material models. However, one may ask whether the term itself was considered as what may also to be found in the semantic field of the word "text" as one might expect from expressions such as "interpretation of a text." This shift in meaning is indeed to be seen in 1891 with Henri
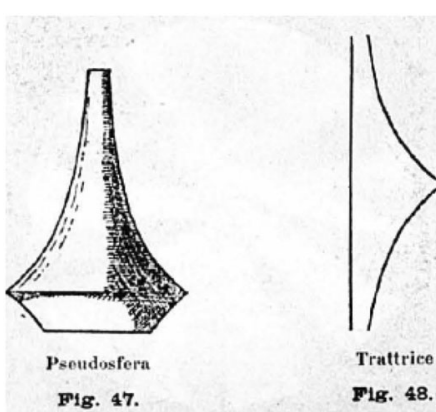

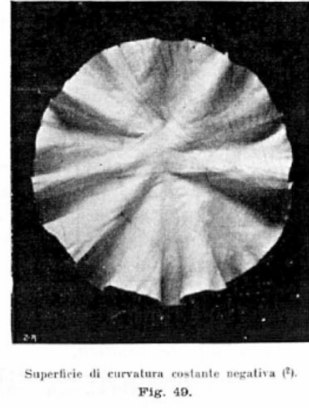

Figure I. Left: Bonola's drawing of the pseudosphere and the tractrix (Bonola 1906, 123). Right: photo of one of Beltrami's models, indicating that it is to be found in the model collection of the mathematical institute in Pavia (ibid., 124).

Poincaré, who coupled the term "interpretation" with other terms: "translation" and "dictionary."14

Poincaré discusses in his paper "Les géométries non euclidiennes" (1891) the different models of hyperbolic geometries, calling them "interpretations." Though he mentions Beltrami's surface of revolution explicitly, he does not note his material models (or any other material models; see Poincaré 1891, 770-771). He then claims, in the section "Interpretation of Non-Euclidean Geometries":

It would be easy to extend Beltrami's reasoning to three-dimensional geometries, and minds that do not recoil before a space of four dimensions will see no difficulty in it ... . I prefer to proceed otherwise. Let us consider a certain plane, which I shall call the fundamental plane, and let us construct a kind of dictionary by making a double series of terms written in two columns, and corresponding each to each, just as in ordinary dictionaries the words in two languages that have the same meaning correspond to each another ... [we can obtain theorems from one interpretation within the second one] as we would translate a German text with the aid of a GermanFrench dictionary (ibid., 771). ${ }^{15}$

Poincaré provides an excerpt from just such a dictionary, as can be seen in Figure 2.

While Poincaré refers to Beltrami's choice of words when he notes that "Lobachevsky's geometry, being susceptible of a concrete interpretation, ceases to be a useless logical exercise (ibid.)," it is clear that with the use of the "dictionary" between two languages, a shift of meaning of

\footnotetext{
${ }^{13}$ The literature on the acceptance of non-Euclidean geometry and the attempts to illustrate and visualize it is immense. For two recent accounts, see Epple 2016 and Gray 2007, 203-232).

${ }^{14}$ This is not by any means to imply that there was no mathematician in the period between Beltrami's work of (1869) and Poincaré's of (1891) who worked on hyperbolic geometry. Thus, for example, in 1871, Felix Klein developed the so-called Cayley-Klein model (based on the work of Arthur Cayley), in which hyperbolic geometry is realized within a circle of the Euclidean plane. The hyperbolic points in this model are the points inside the Euclidean circular disk, while the hyperbolic straight lines correspond to all open chords of the circle bounding the circular disk. In 1880, Poincaré also contributed to the illustration of hyperbolic geometry with two geometric models, the upper half-plane model and the circular disk model (where, in contrast to the Cayley-Klein model, the straight lines correspond to the diameters of the circle $K$ and the arcs of the circle perpendicular to $K$ ).

15 'Il serait aisé d'étendre le raisonnement de M. Beltrami aux géométries a trois dimensions. Les esprits que ne rebute pas l'espace à quatre dimensions n'y verront aucune difficulté ... . Je préfère donc procéder autrement. Considérons un certain plan que j'appellerai fondamental et construisons une sorte de dictionnaire, en faisant correspondre chacun a chacun une double suite de termes écrits dans deux colonnes, de la même façon que se correspondent dans les dictionnaires ordinaires les mots de deux langues dont la signification est la même ... comme nous traduirions un texte allemand a l'aide d'un dictionnaire allemand-français."
} 


\begin{tabular}{|c|c|}
\hline Espuce $\ldots \ldots \ldots \ldots$ & $\begin{array}{l}\text { Portion de l'espace située au-dessus du } \\
\text { plan fondamental. }\end{array}$ \\
\hline Plan. & $\begin{array}{l}\text { Sphère coupant orthogonalement le plan } \\
\text { fondamental. }\end{array}$ \\
\hline Droite. & $\begin{array}{l}\text { Cercle coupant orthogonalement le plan } \\
\text { fondamental. }\end{array}$ \\
\hline Sphère. & Sphère. \\
\hline Ceŕcle. & Cercle. \\
\hline Angle............ & Angle. \\
\hline $\begin{array}{c}\text { Distance de deux } \\
\text { points } \ldots \ldots \ldots \ldots\end{array}$ & $\begin{array}{l}\text { Logarithme du rapport anharmonique } \\
\text { de ces deux points et des intersections } \\
\text { du plan fondamental avec un cercle } \\
\text { passant par ces deux points et le cou } \\
\text { pant orthogonalement. }\end{array}$ \\
\hline
\end{tabular}

Figure 2. Poincaré's translation table (Poincaré 1891, 771). The use of a table that transfers terms from one "language" to another was not new. An obvious example from the beginning of the nineteenth century is Gergonne's two-column method to introduce duality between concepts in the framework of projective geometry.

the expression "interpretation" occurred. For Poincaré, the main point was to show that hyperbolic geometry is consistent, based on the assumed consistency of Euclidean geometry. The way he formulates the following claims underlines how the terms "dictionary" and "translation" functioned together in his discourse:

if two of Lobachevsky's theorems were contradictory, the translations of those two theorems made with the aid of our dictionary would be contradictory as well. But those translations are theorems of ordinary geometry, and no one doubts that ordinary geometry is exempt from contradiction ${ }^{16}$ (ibid.).

It is essential to note that for Poincaré, this "interpretation is not unique, and several dictionaries may be constructed analogous to [the] above" dictionary. This nonuniqueness is reflected in the fact that for Poincaré, the axioms of geometry are conventions and are neither empirical nor a priori synthetic judgments (ibid., 773). Maria de Paz stresses that this concept might have been transferred from the field of jurisprudence, and that Poincaré's use of this concept "implies ... the existence of alternative conventions" (de Paz 2018, 246). ${ }^{17}$ But it is exactly these alternative conventions that reflect the nonuniqueness of the dictionary. Just as there are several possible conventions, there are several possible dictionaries-each dictionary is between two different languages.

Poincaré's "dictionary" and the possibility of using several alternative such dictionaries did not go unnoticed; it was certainly a part of the elaborate and profound mathematical discussion during the 1890 s regarding the nature of the axioms of geometry and the relationships between the theory and the different "systems" satisfying it. Indeed, the term "system" was employed to denote a collection of axioms that satisfy a theory. ${ }^{18}$ Though a discussion of the different concepts and terms that were used by various mathematicians dealing with the foundations of geometry at the end of the nineteenth century (Hermann Wiener, Moritz Pasch, David Hilbert, to name only a few) is beyond the scope of this paper, it is illuminating to give one example from this period. Hilbert, in a letter to Frege on December 29, 1899, wrote the following:

every theory is only a scaffolding [Fachwerk] or schema of concepts together with their necessary relations to one another, and ... the basic elements can be thought of in any way one likes. If in speaking of my points I think of some system of things, e.g. the system: love, law, chimneysweep ... and then assume all my axioms as relations between these things, then my propositions, e.g. Pythagoras' theorem, are also valid for these things. In other words: any theory can always be applied to infinitely many systems of basic elements. One only needs to apply a reversible oneone transformation [Transformation] and lay it down that the axioms shall be correspondingly the same for the transformed things (in Frege 1980, 40-41). ${ }^{19}$

How Hilbert refers to the Pythagorean theorem certainly reminds us of how Husserl, almost thirty years later, would refer to it, as we saw in the introduction; this is perhaps not surprising, given the fact that from their acquaintance in 1901, Hilbert and Husserl were close friends and knew each other's works well (though there were differences in their approaches). ${ }^{20}$ And although Hilbert does not talk about "translation" in 1899 as Poincaré does in 1891, he does talk about "transformation," and one may assume that for Hilbert, in a way resembling Poincaré's dictionary, there was a dictionary transforming the system of points, lines, and planes into the system of love, law, chimneysweep. But whether it is (or may be considered) a "dictionary" or "transformation" from a theory to a system or only from

\footnotetext{
16، "si deux théorèmes de Lowatchewski étaient contradictoires, il en serait de même des traductions de ces deux théorèmes, faites à l'aide de notre dictionnaire. Mais ces traductions sont des théorèmes de géométrie ordinaire et personne ne doute que la géométrie ordinaire ne soit exemple de contradiction."

${ }^{17}$ See also (Zahar 2001, 65-106), especially 78-81, regarding the notion of "translation."

${ }^{18}$ Beginning in the late 1930s, due to the spread of model theory, the term "model" began to be used to denote those systems. See, for example, Mancosu (2006) on Tarski's use of the term. Indeed, it is essential to note that the term "model" was not used in the 1890s and early 1900 s to denote a model in the modern sense of the word, but rather a three-dimensional material model. Hence, when Zahar underlines "Poincaré's use of the notion of a translation rather than of the construction of a model"' (2001, 78), it is a somewhat misleading statement, precisely for the reason given above.

19، Ja, es ist doch selbstverständlich eine jede Theorie nur ein Fachwerk oder Schema von Begriffen nebst ihren nothwendigen Beziehungen zu einander, und die Grundelemente können in beliebiger Weise gedacht werden. Wenn ich unter meinen Punkten irgendwelche Systeme von Dingen, z.B. das System: Liebe, Gesetz, Schornsteinfeger ... denke und dann nur meine sämmtlichen Axiome als Beziehungen zwischen diesen Dingen annehme, so gelten meine Satze, z.B. der Pythagoras auch von diesen Dingen. Mit andern Worten: eine jede Theorie kann stets auf unendliche viele Systeme von Grundelementen angewandt werden. Man braucht ja nur eine umkehrbar eindeutige Transformation anzuwenden und festzusetzen, dass die Axiome für die transformirten Dinge die entsprechend gleichen sein sollen."

${ }^{20}$ For which opinions Husserl and Hilbert shared and on which subjects they had different views, see (Hartimo 2017).
} 
one particular system to another remains somewhat unclear in the letter from 1899.

Poincaré's concepts of "dictionary" and "translation" were also used during the first two decades of the twentieth century. In 1906, the Italian mathematician Roberto Bonola published his influential book La geometria non euclidea: Esposizione storico critica del suo sviluppo. ${ }^{21}$ In that book, Bonola, in the section "Geometry on a surface," first discusses surfaces of constant curvature: positive, zero, or negative. He then presents two drawings: one of the tractrix (together with its equation) and one of the surface of revolution obtained from it, called the "pseudosphere." The section ends with a photograph of one of Beltrami's paper models (see Figure 1 and Bonola 1906, 123-124). Immediately following this discussion, Bonola emphasizes another way of thinking about non-Euclidean geometry:

There is an analogy between the geometry on a surface of constant curvature ... and that of a portion of a plane, both taken within suitable boundaries. We can make this analogy clear by translating the fundamental definitions and properties of the one into those of the other (Bonola 1906, 125).

Also here, the term "translation" appears to show the logical relationships between different terms, which Bonola presents in a translation table.

Bonola's work became quite well known. To give one example, in 1913, Hermann Weyl published his influential book Die Idee der Riemannschen Fläche; but in discussing the non-Euclidean plane, he does not mention any of the material models of Beltrami. He does, however, emphasize a "translation" between basic concepts (points, lines) similar to Bonola's; after this translation, "the complete BolyaiLobachevsky geometry holds for these 'points' and 'straight lines" (Weyl 1913, 152). As a reference for this "model of plane non-Euclidean geometry" (ibid.), Weyl provides the title of the German translation of Bonola's book. Essential to note here is that Weyl employs the term "model" in the sense of a system of concepts and axioms and not in the sense of a material one. ${ }^{22}$ In his book Raum Zeit Materie, Weyl presents Beltrami's "Euclidean model" (1919, 83) of non-Euclidean plane geometry (which holds on a surface of revolution; hence by Beltrami's "model" Weyl does not mean the physical one). But he once again principally stresses the relationship between models of Euclidean and non-Euclidean geometry as a kind of translation between two languages: one constructs a "Euclidean model for the non-Euclidean geometry" and "sets a lexicon by which one translates the concepts of Euclidean geometry into a foreign language, that of non-Euclidean geometry" (ibid., 7172). ${ }^{23}$ Again, Weyl completely ignores Beltrami's paper models and his "interpretations." The concept of "translation" becomes related to other semantic fields, related to "text" and "language." While the term "translation" might have indicated previously a translation between a concrete material interpretation and a set of equations, now it was between two abstract models, consisting solely of concept and axioms.

One should note that the use of the term "translation" between two languages, though echoing the former case study, was not used identically to how Monge, for example, employed it. First, Monge (and several other mathematicians mentioned in the first case study) did not use the term "dictionary" explicitly, and second, Monge (but also Laplace implicitly) pointed toward a certain hierarchy between languages. That is certainly not the case here, since for Poincaré, Bonola, and Weyl, the different interpretations are of the same geometry, having always the same strength. ${ }^{24}$

\section{Case Study III: Bourbaki and the Towers of Babel}

The two previous examples focused on specific time periods in the history of mathematics: the beginning of the nineteenth century and the rise of descriptive geometry and the end of the nineteenth century with the various approaches to non-Euclidean geometry. These two examples show that the term "translation" was used as an epistemic category, that is, as a term expressing certain claims regarding the nature of mathematical knowledge. Its use pointed toward a success - to a certain extent-in expressing a mathematical theorem or system in two languages that are different though translatable into each other. However, the term was also employed to point toward a different conception: to indicate when mathematical domains could not communicate with each other.

This view is to be seen in a short note by the mathematician Felix Klein. In 1926, Klein described several approaches to dealing with algebraic functions at the beginning of the twentieth century-the Italian school of algebraic geometry during the first decades of the twentieth century with its "geometric thinking" and the German school with its "arithmetic procedures"- - and he notes that there is an unsolvable dissonance: "The situation is like the Tower of Babel, that soon the different languages no longer understand each other",25 (Klein 1926a, 327). Klein was referring to the 1916 edition of the Enzyklopädie der mathematischen Wissenschaften, in which a two-column table was included comparing the different terms used in each language (Figure 3). This kind of table, which was already implicitly called by Poincaré a table of "translation,"

\footnotetext{
${ }^{21}$ The book was translated into German in 1908 (as Die nichteuklidische Geometrie. Historisch-kritische Darstellung ihrer Entwicklung) and into English in 1912 (as NonEuclidean Geometry: A Critical and Historical Study of Its Development). I follow here partially the discussion in (Rowe 2017, 8).

${ }^{22}$ Epple (2018) notes that this is not the first use of the word in this sense. In his 1903 inaugural lecture "Das Raumproblem," Hausdorff employs the term "models" (when talking about "Euclidean models for non-Euclidean geometries") as a synonym for "systems" of geometry $(1904,3)$.

23،"stellen [wir] jetzt ein Lexikon auf, durch das die Begriffe der Euklidischen Geometrie in eine fremde Sprache, die 'Nicht-Euklidische,' übersetzt werden."

${ }^{24}$ Although Beltrami indicates that there seems to be a hierarchy of generality, since the translation into the material is partial: one cannot continue the construction of several of the material models to infinity.

${ }^{25}$ Indeed, what emerged from this Tower of Babel is new methods and techniques in algebraic geometry, in the form of Oscar Zariski's arithmetization project of algebraic geometry, which began in the late 1930s; see Slembek (2002).
} 


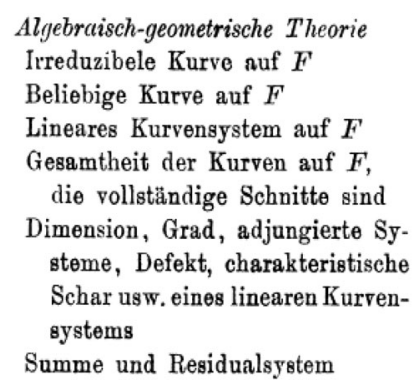

Arithmetische Theorie
Primteiler
Divisor
Divisorenklasse

Hauptklasse

ebenso, einer Klasse

Produkt und Quotient zweier Klassen).

Figure 3. A table of various concepts used in different theories (the "algebraic-geometric" and the "arithmetic") for investigating algebraic functions was added to the Enzyklopädie der mathematischen Wissenschaften, at the beginning of the article "Die algebraischen Flächen vom Gesichtspunkte der birationalen Transformationen aus" of Castelnuovo and Enriques. The editors, Meyer and Mohrmann, noted, "Here is a short table of corresponding basic terms" ["Hier ein kurzes Verzeichnis der einander entsprechenden Grundbegriffe"] (in Enzyklopädie der mathematischen Wissenschaften, 19031915, vol. 3, second part, first half, 676).

was obviously not a novel visual means for showing relationships between different mathematical idioms. ${ }^{26}$

The use of the metaphor of the Tower of Babel was also certainly not new, at least when one considers German philosophical thought from the late eighteenth century to the early twentieth: Kant, Goethe, Hegel, and Benjamin all referred to this architectural metaphor, though having different aims in bringing it to the fore (see Purdy 2011). This is not to imply that Klein was necessarily aware of such philosophical use of this metaphor, but one may assume that he was aware of the use of this architectural metaphor by mathematicians during the late nineteenth century and the beginning of the twentieth (cf. Schlimm 2016). What I would like to focus on, however, is not the architectural metaphor and how it reflected the conception of mathematics as a language constructed by man, but rather how the image of the Tower of Babel was associated with a global task of translation. The intertwining of the two terms is to be found explicitly in the work of Bourbaki.

To recall, Nicolas Bourbaki was the pseudonym of a group of (mainly French) mathematicians who, starting at the end of 1934, met regularly and attempted to reformulate mathematics in a modern and rigorous way, writing selfcontained and up-to-date books that, based on set theory, would unify many branches of mathematics. In order to see how the two concepts - that of translation and that of the Tower of Babel-appear in the writings of Bourbaki, I will focus on two of their works: the first, their manifesto of 1948, translated into English in 1950, called "The Architecture of Mathematics"; the second, their 1968 book Theory of Sets.

In "The Architecture of Mathematics," the term "translation" appears only once, and it is used in a similar sense to how Hilbert described the passage from an abstract theory to a concrete system ("model" in today's terminology) satisfying the axioms of the theory. In talking about three of the axioms of a group, Bourbaki emphasizes that

one can take the[se] three following [axioms], which we shall express by means of our symbolic notation ... which it would be very easy to translate into the particular language of each [example discussed] (Bourbaki 1950, 224).

However, another conception of translation arises implicitly in the manifesto. Bourbaki, like Klein, also evokes the metaphor of the Tower of Babel in regard to the languages of mathematics:

it is legitimate to ask whether this exuberant proliferation [of mathematics] makes for the development of a strongly constructed organism ... or whether it is the external manifestation of a tendency towards a progressive splintering, inherent in the very nature of mathematics, whether the domain of mathematics is not becoming a Tower of Babel, in which autonomous disciplines are being more and more widely separated from one another, not only in their aims, but also in their methods and even in their language (ibid., 221).

One may wonder where Bourbaki's metaphor of Tower of Babel originated. While it is somewhat improbable that it was taken directly from Klein's remark, one possible source is André Weil's 1946 book Foundations of Algebraic Geometry. Weil was an early member of the Bourbaki group during the 1930s, and hence one can assume that the other members of the group knew his book. In the preface to that book, Weil (1946, viii) expresses his wish that all mathematicians (or at least those who deal with algebraic geometry) would speak one clear and well-defined language, avoiding the fate of the Tower of Babel:

attention must be and has been given to the language and the definitions. Of course every mathematician has a right to his own language - at the risk of not being understood ... [leading to the] same fate ... for mathematics as once befell, at Babel ... in such a subject as algebraic geometry, where earlier authors left many terms incompletely defined ... all terms have to be defined anew, and to attach precise meanings to them is a task not unworthy of our most solicitous attention.

I would like to suggest that Weil and Bourbaki both claim that in order to prevent the danger arising from this "Tower of Babel" (that is, against the dangerous splintering), one should employ a mathematical machinery called "formalism," by means of which mathematical proofs can be

\footnotetext{
${ }^{26}$ Moreover, Klein himself used the term "translation" to describe relationships between different mathematical languages. For example, "The geometric considerations that we have made here following Chasles will now be translated into the language of analysis" (1926b, 29). Or this: "In Plücker's geometry, the bare combination of equations is translated into geometric terms, through which the analytic operations are carried out in reverse" (1926a, 122). This use of "translation", seems to mirror that of Monge.
} 
translated, as stated in Bourbaki's book Theory of Sets. ${ }^{27}$ As stated in the introduction of the book, the mathematician

[in] general is content to bring the exposition to a point where his experience and mathematical flair tell him that translation into formal language would be no more than an exercise of patience (Bourbaki 1968, 8).

However, while the first conception of translation, proposed in the 1948 manifesto, was more local, in the sense that one transforms a particular theory into concrete examples, here one deals with a global translation: the translation of the entire body of mathematics into the "single formalized language" of set theory (ibid., 9). However, Bourbaki admits that writing down everything in a formalized language would be a "tedious" exercise ${ }^{28}$ (ibid., 8), almost impossible, and eventually notes that their book would be just like any other book on mathematics. They eventually declare that "[w]e shall therefore very quickly abandon formalized mathematics" (ibid., 11).

\section{“Translation" as an Epistemological Category: Toward Trading Zones between Mathematical Domains}

Although in all of the above case studies the term "translation" was considered in the semantic field of other textand language-related concepts (such as "dictionary," "language," "interpretation"), there are clear differences among the three studies. One major difference between the approach of Bourbaki to the term "translation" (and the activity itself) and those presented in the first two case studies concerns their domain of applicability: while the actors in the first two case studies concentrated on local domains of mathematical practices and research (descriptive geometry and the analytic vs. geometric idioms, or non-Euclidean geometry and its different models),
Bourbaki's concept of translation is global: the official aim is to translate the entire body of mathematics into a single language. In this sense, it reflects Husserl's approach, that geometry has only one language, "and within each language it is again the same," to cite Husserl again.

To make a necessary detour, it should be emphasized that neither Bourbaki nor Husserl thought that with the formalization into a single language, or its use, mathematical research and development would be either stopped or completed. This was already seen with Bourbaki's explicit image of incessant splintering and the implicit construction of the Tower of Babel. But Husserl was also aware of that; in a slightly different version of The Crisis of European Sciences and Transcendental Phenomenology, ${ }^{29}$ he employs the same metaphor of the Tower of Babel, as Bourbaki did several years afterward. Recalling the different mathematical cultures that existed before and along with that of Greek antiquity - the Egyptians, the Babylonians, and the Indians-Husserl notes:

Only Greek philosophy leads in its own development to the science of infinite theories, in which Greek geometry was the dominant example and model for thousands of years. Mathematics, the idea of the infinite, that of infinite tasks, is a Babylonian tower construction that despite its endlessness, remains a sensible task ad infinitum. The correlate of such infinitude is the new man, the man of infinite goals (Husserl 1987, 44, 46)..$^{30}$

That is, Husserl notes that mathematics is an infinite project, echoing the infinite, never-ending construction embodied in the Tower of Babel project. ${ }^{31}$ The task, however, is to ground mathematics in a single language; indeed, "Euclidean geometry, and ancient mathematics in general, knows only finite tasks, a finitely closed a priori,"32 (Husserl 1970, 21).

\footnotetext{
${ }^{27}$ As a side note, one should add that formalization, which would prevent the miscommunication and misunderstanding stemming from the mathematical "Tower of Babel," was also considered in 1994, years after the Bourbaki manifesto, in the "QED Manifesto." As the anonymous writer of that manifesto notes, "QED is the very tentative title of a project to build a computer system that effectively represents all important mathematical knowledge and techniques. ... the increase of mathematical knowledge during the last two hundred years has made ... mathematical results something beyond the capacity of any human. ... The QED system we imagine will provide a means by which mathematicians and scientists can scan the entirety of mathematical knowledge for relevant results and, using tools of the QED system, build upon such results with reliability and confidence ..." (N.N. 1994, 238). This computerized formal system of QED would enable one to overcome "the Babel of incompatible reasoning systems and symbolic computation" (ibid., p. 242). I thank Stephanie Dick for pointing this out during her talk "QED" on September 28, 2019, at the workshop Narrative and Mathematical Argument at the London School of Economics.

${ }^{28}$ Bourbaki also notes that "the task of writing out our proofs in this [formalized] language ... is far from being as simple as that, and no great experience is necessary to perceive that such a project is absolutely unrealizable: the tiniest proof at the beginning of the Theory of Sets would already require several hundreds of signs for its complete formalization. Hence, from Book I of this series onwards, it is imperative to condense the formalized text by the introduction of a fairly large number of new words (called abbreviating symbols) and additional rules of syntax (called deductive criteria). By doing this we obtain languages which are much more manageable than the formalized language in its strict sense" $(1968,10)$.

${ }^{29}$ This manuscript is denoted as (Ms M III 5 IIb), which differs in a few places from the version known as (Ms M III 5 II a), which was the version translated into English. See (Strasser 1987).

30" Nur die griechische Philosophie leitet in eigener Entwicklung zur Wissenschaft unendlicher Theorien, darin das jahrtausend-beherrschende Exempel und Vorbild die griechische Geometrie war. Die Mathematik, die Idee des Unendlichen, die der unendlichen Aufgaben, ist ein babylonischer Turmbau, der trotz seiner Endlosigkeit doch eine in infinitum sinnvolle Aufgabe bleibt. Das Korrelat solcher Unendlichkeit ist der neue Mensch, des Mensch unendlicher Ziele" (translated into English by M.F.). ${ }^{31}$ Jacques Derrida, in his commentary to Husserl's Origin of Geometry, notes that this attributes "infinitization ... to Greek philosophy and geometry, i.e., the creative idealization of mathematics in general" (Derrida 1989, 129)

${ }^{32}$ One might argue that this argument applies only to ancient mathematics; however, a few sentences before, Husserl describes Euclidean geometry as what having the characteristics of modern geometry (of the end of the nineteenth century, beginning of the twentieth century): "[W]ith Euclidean geometry had grown up the highly impressive idea of a systematically coherent deductive theory, aimed at a most broadly and highly conceived ideal goal, resting on 'axiomatic' fundamental concepts and principles" (Husserl 1970, 21).
} 
It is interesting to note that one can read Husserl, as Jacques Derrida does, ${ }^{33}$ in two almost contradictory ways: on the one hand, Husserl calls for a destruction of the mathematical Tower of Babel, since as the project fails eventually, one needs a univocal language to make "a decisive rupture with spontaneous language" in order "to fix meanings"; 34 on the other hand, Husserl calls for the construction of the very same tower, since only in that way would one have access to this univocity, via the comparison between the original and its "translations"—although this access would be "inauthentic and indirect." 35

One has to emphasize yet again that the global translation project into a formalized language was considered in the 1950 s to be a theoretical one (i.e., it was never done or even attempted in practice). It can be suggested that the project was announced to give it greater prestige by establishing it with a more rigorous basis, hence prompting a vertical image of translation. "Translations" that are $l^{36}$ cal appear, as claimed above, when mathematicians deal in practice with translating, concentrating on a specific restricted field in mathematics.

And while Husserl's reflections are highly philosophical, they underline, although implicitly, similar reflections that were discussed when various mathematicians dealt with local translations. One may hence also interpret Husserl's example of the Pythagorean theorem as emphasizing a concrete theorem: his claim for the indirect access to the ideal sense of the mathematical expression due to translations may underline a philosophical approach to the limits of local translations. One may even suggest that Husserl is underlining the limits of local translations, in the sense that if every translation is "inauthentic and indirect," then also every equivalence relation between mathematical idioms cannot be without discrepancies.

This local versus global approach to "translation" between different idioms of scientific languages has also been present in discussions within the philosophy of science. For example, Thomas Kuhn emphasizes the problematic of using the concept of "translation" with respect to the communication between different scientific practices and languages. In 1970, he noted the use of a universal language that would be able to display all scientific idioms "as one":

The point-by-point comparison of two successive theories demands a language into which at least the empirical consequences of both can be translated without loss or change. That such a language lies ready to hand has been widely assumed since at least the seventeenth century when philosophers ... sought a "universal character," which would display all languages for expressing them as one (Kuhn 1970, 266).

Kuhn criticized this positivist idea that scientific knowledge can be built upon neutral empirical ground:

Why is translation, whether between theories or languages, so difficult? Because, as has often been remarked, languages cut up the world in different ways, and we have no access to a neutral sub-linguistic means of reporting (ibid., 268).

If one follows Bourbaki and applies Kuhn's description to mathematics, this neutral language-as the only universal language - is the one to be found at the basis of mathematics, as is implied by the prefix "sub." What is here presented is a pursuit of a universally accepted single language, but which is-according to Kuhn-absent and impossible to find. ${ }^{37}$

One may quite rightly argue that Kuhn's description refers to scientists who research the same object with different scientific languages, and this is not the case with mathematicians, who may consider different idioms and translate between them. While this critique might be applied to Bourbaki's description of a global translation from (in theory) any mathematical idiom and practice into a formalized language, in most of the examples we examined above, mathematicians were actually looking at the same set of objects and theorems (curves and surfaces in descriptive geometry or models of hyperbolic geometry), described in (at least) two different ways. They did not make any claims of being global, and certainly did not express a holistic point of view regarding mathematics, but rather expressed relationships of "translation" between more local domains of mathematics. It is useful to think of this relation in terms of Peter Galison's "trading zones." According to Galison, a trading zone is "an intermediate domain in which procedures could be coordinated locally even where broader meanings clashed" (Galison 1997, 46). Since trading zones express "different subcultures of theorizing" (ibid.) and how the interaction between the different subcultures develops, it takes history into account.

\footnotetext{
${ }^{33}$ Note also Derrida's work on translation and the Tower of Babel from 1980: Des Tours de Babel. The English translation in is (Derrida 1985).

${ }^{34}$ (Derrida 1984, 100-101, footnote 108). This is Derrida's assumption regarding the purpose of univocity.

35 "for them [the objective sciences] the difference between the original language of the work and its translation into other languages does not remove its identical accessibility [to the ideal sense of the original expression]; rather, it renders the access only inauthentic and indirect" (Husserl 1970, 357 , FN *, translation changed) ["für die der Unterschied zwischen der Originalsprache des Werkes und der Übersetzung in fremde Sprachen die identische Zugänglicheit nicht aufhebt bzw. nur zu einer uneigentlichen, indirekten macht.']

${ }^{36}$ David Bellos describes translations between spoken languages as having a vertical character: "Translation UP [is] [a translation] towards a language of greater prestige than the source. ... Translations towards the more general and more prestigious tongue [that is, translations UP] are characteristically highly adaptive, erasing most of the traces of the text's foreign origin" (Bellos 2011, 172-173). In this sense, formalization can be considered a "translation UP," since formalized language is presented as a more rigorous language: the goal is to find more stable foundations. Hence Bellos's image should be turned on its head, literally speaking: for Bourbaki, achieving a translation UP into a formal language is done by making sure that the basis and the foundations of mathematics are stable (or more stable) by reducing everything (theoretically) to a formal language.

${ }^{37}$ The solution that Kuhn proposes is the following: when two scientific traditions confront each other, a communication can occur only by a paradigm shift: "In the absence of a neutral language, the choice of a new theory is a decision to adopt a different native language and to deploy it in a correspondingly different world" (Kuhn 1970, 277).
} 
In this sense, seeing "translation" between local but different mathematical idioms as a "trading zone" concentrates on the local coordination between those idioms, and certainly not on their homogenization by establishing a "universal language" (as is done by the "global translation" project; cf. Galison 1999, 145, 157).

This local mathematical "trading zone" is also to be observed in the last example I would like to present. In 1950, the mathematician Emil Artin published a paper entitled "The Theory of Braids," a presentation to the general public of his research in braid theory (cf. Friedman 2019). Artin states:

The theory of braids shows the interplay of two disciplines of pure mathematics: topology, used in the definition of braids, and the theory of groups, used in their treatment (Artin 1950).

While several statements are proved only symbolically, other results are described by requiring the reader to imagine the stretching of several threads and by referring to a diagram. Regarding these results, Artin states that one can "describe the translation of our geometric procedure into group theoretical language." A few paragraphs later, Artin notes that "the problem of classification of closed braids, at least, can be translated into a group theoretical problem" (ibid., 119). One may assume that Artin used the term "translation" to describe the relationship between the two languages: the diagrammatic-topological and the symbolic-algebraic. However, this translation was restricted to only parts of these idioms, as is to be seen from another paper of Artin's, "Theory of Braids," published in 1947. Presenting in this paper the theory of braids in a more algebraic idiom, Artin strongly discourages the reader from either imagining or drawing certain braids, explicitly encouraging working only with algebraic expressions. After presenting an example of a certain normal form of a braid, both algebraically and with the help of a drawing, he emphasizes: "Although it has been proved that every braid can be deformed into a ... [specific] normal form, the writer is convinced that any attempt to carry this out on a living person"- that is, drawing it- "would only lead to violent protests and discrimination against mathematics" (Artin 1947, 126). This underlines that for Artin, "translation" is a restricted epistemic category: it may help in understanding theorems and concepts or even prompt the emergence of new knowledge, but it should not be applied to every algebraic proposition in order to visualize its objects or its results.

Seeing the term "translation" in this way-as pointing toward an epistemic activity whose domain of action is restricted and local-helps to frame how the actors considered themselves and their activity while engaged in "translating." If this activity is between two local domains, which from time to time have to be coordinated and adjusted, this means that a complete dictionary is not given in advance. Hence "translation" is not just a description of an already given procedure, but rather an operative, constitutive action, which enables the emergence of new knowledge, but at the same time may also be restrictive, in the sense that it may be that not all of the theorems, objects, and procedures in the first domain can be and are being translated into the second. This restriction occurs, for example, with Weyl (and also implicitly Poincaré) ignoring Beltrami's paper models, ${ }^{38}$ with Laplace's preference for the "algebraic language," and with Monge's explicitly noting that translation would work but only "if the problems have no more than three unknowns," implying that if a problem had more than three variables, then no translation into the language of geometry would be possible. The last example of Artin's shows this restrictedness clearly; indeed, Artin dramatically ends his paper with a warning against the "violent protests" that might erupt were such a "translation" to occur. To recall Monge: just "as every analytic operation can be regarded as the script for a spectacle in geometry," this spectacle itself has its limits, just as "translation" as an epistemic category was employed as a local and at times restricted one, in opposition to the HusserlBourbaki impractical dream of a single universal language.

\section{ACKNOWLEDGMENTS}

Open Access funding provided by Projekt DEAL. A preliminary version of this paper was presented at the Congress of Logic, Methodology and Philosophy of Science and Technology (CLMPST), August 5-10, 2019, at the Czech Technical University, Prague, and at the workshop Narrative and Mathematical Argument (organized by Prof. Mary S. Morgan and Dr. Dominic Berry), September, 28, 2019, at the London School of Economics. I thank the participants at both venues for fruitful conversations. The research for this paper was funded by the Deutsche Forschungsgemeinschaft (DFG, German Research Foundation) under Germany's Excellence Strategy_EXC 2015/1.

Open Access This article is licensed under a Creative Commons Attribution 4.0 International License, which permits use, sharing, adaptation, distribution and reproduction in any medium or format, as long as you give appropriate credit to the original author(s) and the source, provide a link to the Creative Commons licence, and indicate if changes were made. The images or other third party material in this article are included in the article's Creative Commons licence, unless indicated otherwise in a credit line to the material. If material is not included in the article's Creative Commons licence and your intended use is not permitted by statutory regulation or exceeds the permitted use, you will need to obtain permission directly from the copyright holder. To view a copy of this licence, visit http://creativecommons.org/licenses/by/4.0/.

Michael Friedman

Cluster of Excellence "Matters of Activity. Image Space Material"

Humboldt-Universität zu Berlin

Unter den Linden 610099 Berlin

Germany

e-mail: michael.friedman@hu-berlin.de

\footnotetext{
${ }^{38}$ One may claim that not including the material models in the discussion just shows a lack of interest and not a lack of translatability on the part of Weyl. While this might be true, Weyl's decision not to mention them while using the term "translation" and at the same time citing Bonola underlies a shift and at the same time a restriction in how the term "translation" and the associated operation functioned.
} 


\section{REFERENCES}

Emil Artin, 1947. Theory of braids. Annals of Mathematics, Second Series 48:1, 101-126.

Emil Artin, 1950. The theory of braids. American Scientist 38:1, 112119.

Évelyne Barbin, 2019a. Monge's descriptive geometry: his lessons and the teachings given by Lacroix and Hachette. In Descriptive Geometry, The Spread of a Polytechnic Art. International Studies in the History of Mathematics and Its Teaching, edited by Évelyne Barbin, Marta Menghini, and Klaus Volkert. pp. 3-18. Springer.

Évelyne Barbin, 2019b. Descriptive geometry in France: circulation, transformation, recognition (1795-1905). In Descriptive Geometry, The Spread of a Polytechnic Art. International Studies in the History of Mathematics and Its Teaching, edited by Évelyne Barbin, Marta Menghini, and Klaus Volkert. pp. 19-38. Springer.

Hans Blumenberg, 1957. Licht als Metapher der Wahrheit. Studium Generale 10, 432-447.

David Bellos, 2011. Is That a Fish in Your Ear? Translation and the Meaning of Everything. Faber and Faber.

Eugenio Beltrami, 1868. Saggio di interpretazione della geometria noneuclidea. In Opere matematiche di Eugenio Beltrami, vol. 1, pp. 374-405. Mapli.

Jean-Baptiste Biot, 1802. Essai de Géométrie analytique appliquée aux courbes et aux surfaces du second ordre. Crapelet.

Roberto Bonola, 1906. La geometria non euclidea: Esposizione storico critica del suo sviluppo. Zanichelli.

Nicholas Bourbaki, 1950. The architecture of mathematics. American Mathematical Monthly 57:4, 221-232.

Nicholas Bourbaki, 1968. Theory of Sets. Springer.

Maria de Paz, 2018. From jurisprudence to mechanics: Jacobi, Reech, and Poincaré on convention. Science in Context 31:2, 223-250.

Jacques Derrida, 1984. Two words for Joyce. In Post-Structuralist Joyce: Essays from the French, edited by Derek Attridge, pp. 145-160. Cambridge University Press.

Jacques Derrida, 1985. "Des Tours de Babel." In Difference in Translation, edited by Joseph F. Graham, pp. 165-207. Cornell University Press.

Jacques Derrida, 1989. Edmund Husserl's Origin of Geometry: An Introduction. University of Nebraska Press.

Jean Dhombres (ed.), 1992. L'École normale de l'an III. Vol. 1, Leçons de mathématiques. Laplace - Lagrange - Monge. Dunod.

Moritz Epple, 2016. "Analogien," "Interpretationen," “"Bilder," “'Systeme" und "Modelle": Bemerkungen zur Geschichte abstrakter Repräsentationen in den Naturwissenschaften seit dem 19. Jahrhundert. Forum Interdisziplinäre Begriffsgeschichte 5:1, 1130.

Moritz Epple, 2018. "Analogies," "interpretations," "'images," "'systems," and "models": on the history of abstract representation in the mathematical sciences since the nineteenth century. Talk on July 26, 2018, at the workshop "Model and Mathematics," Cluster of Excellence "Image Knowledge Gestaltung," Humboldt University, Berlin.

Gottlob Frege, 1980. Philosophical and Mathematical Correspondence. Basil Blackwell.

Michael Friedman, 2018. A History of Folding in Mathematics. Mathematizing the Margins, Birkhäuser.
Michael Friedman, 2019. Mathematical formalization and diagrammatic reasoning: the case study of the braid group between 1925 and 1950. British Journal for the History of Mathematics 34:1, 43-59.

Peter Galison, 1999. Trading zone: coordinating action and belief. In The Science Studies Reader, edited by Mario Biagioli, pp. 137160. Routledge.

Peter Galison, 1997. Image and Logic-A Material Culture of Microphysics. University of Chicago Press.

Jeremy Gray, 2007. Worlds out of Nothing. Springer.

Mirja Hartimo, 2017. Husserl and Hilbert. In Essays on Husserl's Logic and Philosophy of Mathematics, edited by Stefania Hartimo, pp. 245-263. Springer.

Felix Hausdorff, 1904. Das Raumproblem. Annalen der Naturphilosophie 3, 1-23.

Edmund Husserl, 1970. The Crisis of European Sciences and Transcendental Phenomenology, translated by David Carr. Northwestern University Press.

Edmund Husserl, 1987. La Crise de l'humanité européenne et la philosophie, translated by Paul Ricoeu. Éditions bilingue. Aubier.

Felix Klein, 1926a. Vorlesungen über die Entwicklung der Mathematik im 19. Jahrhundert, vol. 1. Springer.

Felix Klein, 1926b. Vorlesungen über Höhere Geometrie, edited by W. Blaschke. Springer.

Thomas S. Kuhn, 1970. Reflections on my critics. In Criticism and the Growth of Knowledge, edited by Imre Lakatos and Alan Musgrave, pp. 231-278. Cambridge University Press.

Sylvestre François Lacroix, 1797. Traité du calcul différentiel et du calcul intégral. J.M. Duprat.

Brendan Larvor, 2019. From Euclidean geometry to knots and nets. Synthese 1967, 2715-2736.

Paolo Mancosu, 2006. Tarski on models and logical consequence. In The Architecture of Modern Mathematics, edited by José Ferreirós and Jeremy Gray, pp. 209-238. Oxford University Press.

Gaspard Monge, 1799. Géométrie descriptive. Leçons données aux écoles normales l'an 3 de la république. Baudouin.

N.N., 1994. The QED manifesto. In Automated Deduction - CADE 12, Lecture Notes in Artificial Intelligence 814, pp. 238-251. Springer.

Henri Poincaré, 1891. Les géométries non euclidiennes. Revue générale des sciences 2, 769-774.

Daniel L. Purdy, 2011. On the Ruins of Babel. Architectural Metaphor in German Thought. Cornell University Press.

David E. Rowe, 2017. On building and interpreting models: four historical case studies. Mathematical Intelligencer 39:2 (2017), 6-14.

Joël Sakarovitch, 1998. Épures d'architecture. De la coupe des pierres à la géométrie descriptive XVle-XIXe siècles. Birkhäuser.

Dirk Schlimm, 2016. Metaphors for mathematics from Pasch to Hilbert. Philosophia Mathematica 24:3, 308-329.

Silke Slembek, 2002. Oskar Zariski und die Entstehung der modernen algebraischen Geometrie. Doctoral thesis, Mainz/Strasbourg.

Stefan Strasser, 1987. Preface. In Edmund Husserl, La Crise de l'humanité européenne et la philosophie, translated by Paul Ricoeur, éditions bilingue, pp. 5-10. Aubier.

André Weil, 1946. Foundations of Algebraic Geometry. American Mathematical Society. 
Hermann Weyl, 1913. Die Idee der Riemannschen Fläche. B.G. Teubner.

Hermann Weyl, 1919. Raum Zeit Materie, 3rd edition. Springer.

Ellie Zahar, 2001. Poincaré's Philosophy. From Conventionalism to

Phenomenology. Open Court.
Publisher's Note Springer Nature remains neutral with regard to jurisdictional claims in published maps and institutional affiliations. 